www.jmscr.igmpublication.org

Impact Factor (SJIF): 6.379

Index Copernicus Value: 71.58

ISSN (e)-2347-176x ISSN (p) 2455-0450

crossref DOI: https://dx.doi.org/10.18535/jmscr/v6i6.156

Journal Of Medical Science And Clinical Research

$\underline{\text { Original Article }}$

\title{
Effectiveness of Oral Iron Regimens on Hematological Parameters in Pregnant Women Presenting with Iron Deficiency Anemia (IDA) in Tertiary Care Hospital
}

\author{
Authors \\ Dr Ashish Ranjan ${ }^{1}$, Dr Gaurav Tiwary ${ }^{2}$, Dr G.P.Singh ${ }^{3}$, Dr Deepak Kumar ${ }^{4}$, \\ Dr Satyendra Pathak ${ }^{5}$ \\ ${ }^{1,2}$ Tutor, Department of Pharmacology, Sri Krishna Medical College, Muzaffarpur \\ ${ }^{3}$ Professor \& HOD, Department of Pharmacology, Sri Krishna Medical College, Muzaffarpur \\ ${ }^{4}$ Associate Professor, Department of Pharmacology, Sri Krishna Medical College, Muzaffarpur \\ ${ }^{5}$ Associate Professor, Department of Pharmacology, Sri Krishna Medical College, Muzaffarpur \\ Corresponding Author \\ Dr Deepak Kumar
}

Associate Professor, Department of Pharmacology, Sri Krishna Medical College, Muzaffarpur, India

\begin{abstract}
Objective: Present study was longitudinal and randomized study. The Aim of present study was to evaluate the relative effectiveness of two different oral Iron regimens on hematological parameters among anemic pregnant woman.

Material and Methods: A total of 64 pregnant anemic woman having hemoglobin level between $7 \mathrm{mg} / \mathrm{dl}$ to $11.5 \mathrm{gm} / \mathrm{dl}$ with no any obstetric complications attending the GOPD were selected for study. All the pregnant women were divided in two groups according to Iron supplement. Group A: pregnant woman $(n=32)$ was receiving $200 \mathrm{mg}$ of oral iron supplement once daily and Group B: pregnant woman $(n=32)$ were taking $200 \mathrm{mg}$ of oral iron supplement twice weekly. Follow up visit were planned after every 4 weeks and total duration of study was 12 weeks. In each follow up thorough physical and clinical examination was done, any side effect after taking iron supplements were noted, after that blood sample was taken for evaluation of hematological parameter (Hemoglobin, RBC count, Hematocrit, MCV, MCH, $M C H C$, Reticulocyte count and serum ferritin). All the test were run on fully automated five part CBC machine supplied by Horiba.

Results: All the hematological parameter showed significant improvement in both the study groups. Hemoglobin, hematocrit and RBC count showed a non significant better response in twice weekly group. While MCH, MCHC and Reticulocyte count showed a significant better response in twice weekly group. $M C V$ showed a significant better response in daily group.

Conclusion: Twice weekly iron supplementation is equally effective to treat anemia during pregnancy. Daily iron intake results in greater increase in $M C V$ which might be an additional cause of physiological macrocytosis.

Keywords: Iron deficiency anemia (IDA), MCH, MCHC, MCV, Reticulocyte count, Hemoglobin, RBC.
\end{abstract}




\section{Introduction}

Iron deficiency anemia is considered as the most widespread nutritional deficiency. It affects people of all ages and of both developed and developing countries. Severe Anemia in the first half of pregnancy has been proved to be associated with preterm delivery and small for gestational age fetus Anemia of pregnancy, directly or indirectly contributes to a significant proportion of maternal deaths as well. Among the general measures to control iron deficiency the, oral iron supplement program is the most practical short-terms approach to alleviate the problem, Either daily or weekly, iron supplements are required in iron deficiency anemia, as they improves in preterm labor and birth weight. Significantly low Hemoglobin Percentage and packed cell volume in pregnancy is due in part to dietary iron deficiency, therefore iron therapy is helpful to maintain the Hemoglobin Percentage and PCV nearer to that of non-pregnant women. Also low serum iron and high Total iron binding capacity (TIBC) in pregnant women is due to dietary iron deficiency therefore needed to be corrected with iron supplements. Although iron supplements are required to maintain the iron requirements of mother and her developing fetus during pregnancy, still there are some doubts about their relative benefits. To solve the problems, different does are being in use to correct iron supplements should not be used on daily basis. Studies have been carried out both in laboratory setups and in clinical trials. These studies have concluded that with the use of iron supplementation on daily basis, the constant gut mucosal iron load is reduced. This over load usually accompanies daily supplementation. When this burden is reduced, iron absorption occurs more efficiently and about 2.6 folds increase in absorption is screen. This iron over load not only decrease iron absorption but might also be a cause of oxidative stress and decreased absorption of other micro nutrients. Based on these views some studies suggest intermittent iron supplement and even suggest that weekly supplement to adolescent girls should be universally started to correct that iron store

\section{Materilas and Methods}

Present study was the randomized and longitudinal study which compare the hematological effect of daily and twice weekly iron supplement which was given to the pregnant woman with IDA, conducted in the Department of Pharmacology, Sri Krishna Medical College, Muzaffarpur, with the help of obstetrics and Gynecology Department, during the period of October 2017 to April 2018. A total of 64 pregnant women, attending the outpatient department with single fetus of gestational age of 16 weeks and above with Hemoglobin value between $7 \mathrm{~g} / \mathrm{dl}$ to $11.5 \mathrm{~g} / \mathrm{d} 1$ with no obstetric complications or any co- morbidity, were eligible for study. Women with history of any drug intake or iron supplements in current pregnancy or intolerant to iron supplements in any previous pregnancy were not included in the study. At the time of enrollment detailed history was obtained. In addition a detailed general physical and clinical examination was carried out including gestational age of fetus. Gestational age was investigated by both by the date of last menstrual period and ultrasound. Other information included height, weight and blood pressure. From all the women written informed consent was taken. Eligible women were categories in two groups. Group A: Pregnant women receiving 200mg ferrous sulphate daily $+500 \mathrm{mg}$. elemental calcium once daily + vitamin C $500 \mathrm{mg}$. once daily $(\mathrm{n}=32$.) Group B: Women receiving $200 \mathrm{mg}$ ferrous sulphate twice weekly $+500 \mathrm{mg}$. elemental calcium once daily + vitamin C $500 \mathrm{mg}$. once daily $(n=32)$. Follow up visit were planned after every 4 weeks and total duration of study was 12 weeks. In each follow up thorough physical and clinical examination was done, any side effect (Nausea, vomiting, diarrhea and constipation ) after taking iron supplements were noted, after that Blood sample was taken for evaluation of hematological parameter (Hemoglobin, RBC 
count, Hematocrit, $\mathrm{MCV}, \mathrm{MCH}, \mathrm{MCHC}$, Reticulocyte count and serum ferritin). All the test were run on fully automated five part CBC machine supplied by Horiba.

\section{Results}

Hemoglobin concentration and RBC indices of two groups were not much different at the beginning of therapy. Although they were either at lower side of normal value or below normal limits. All these parameters showed significant improvement after the completion of therapy.
These improvements were seen in both groups when pretreatment and post treatment value were compared. Except for hematocrit all the parameters of both groups were when compared with their pretreatment values. Hemoglobin, hematocrit and RBC count showed a no significant better response in twice weekly group. $\mathrm{MCH}, \mathrm{MCHC}$ and reticulocyte count showed a significant better response when compared to twice weekly group. Hematological parameters before and after the treatment are shown in table. 1

Table - 1 Hematological Pattern of Pregnant Women after Iron supplement, at $1^{\text {st }}$ week, $4^{\text {th }}$ week, $8^{\text {th }}$ week and $12^{\text {th }}$ week visit, according to Daily Dose Or twice weekly Dose.

\begin{tabular}{|l|c|c|c|c|c|}
\hline \multirow{2}{*}{$\begin{array}{l}\text { Hematological } \\
\text { Parameter }\end{array}$} & $\begin{array}{c}\text { Iron Supplement } \\
(\mathbf{2 0 0} \text { mg Ferrous } \\
\text { Sulphate) }\end{array}$ & $\begin{array}{c}\mathbf{1}^{\text {st }} \\
\text { effect }\end{array}$ & $\begin{array}{c}\mathbf{4}^{\text {th }} \text { week } \\
\text { effect }\end{array}$ & $\begin{array}{c}\mathbf{8}^{\text {th }} \text { week } \\
\text { effect }\end{array}$ & $\begin{array}{c}\mathbf{1 2}^{\text {th }} \text { week } \\
\text { effect }\end{array}$ \\
\hline \multirow{2}{*}{ Hemoglobin } & Daily Dose & $9.3 \pm 2.2$ & $9.8 \pm 2.3$ & $10.5 \pm 2.1$ & $11.93 \pm 2.4$ \\
\cline { 2 - 6 } & Twice weekly Dose & $9.41 \pm 2.3$ & $10.2 \pm 2.2$ & $11.9 \pm 2.2$ & $12.5 \pm 2.6$ \\
\cline { 2 - 6 } & Daily Dose & $3.62 \pm 0.8$ & $3.81 \pm 1.0$ & $3.86 \pm 1.2$ & $4.16 \pm 1.3$ \\
\cline { 2 - 6 } & Twice weekly Dose & $3.63 \pm 1.1$ & $3.86 \pm 1.2$ & $4.12 \pm 1.3$ & $4.42 \pm 1.5$ \\
\hline \multirow{2}{*}{ Hematocrit } & Daily Dose & $34.3 \pm 2.42$ & $34.6 \pm 1.2$ & $34.9 \pm 1.2$ & $35 \pm 1.4$ \\
\cline { 2 - 6 } & Twice weekly Dose & $34.5 \pm 1.8$ & $34.1 \pm 2.5$ & $33.9 \pm 1.8$ & $34.8 \pm 1.6$ \\
\hline \multirow{2}{*}{ MCH } & Daily Dose & $83.72 \pm 3.4$ & $84.68 \pm 3.6$ & $86.26 \pm 4.1$ & $90 \pm 2.4$ \\
\cline { 2 - 6 } & Twice weekly Dose & $84.12 \pm 2.8$ & $84.69 \pm 3.2$ & $86 \pm 6.4$ & $88 \pm 6.9$ \\
\hline \multirow{2}{*}{ MCHC } & Daily Dose & $26.8 \pm 2.8$ & $27.4 \pm 3.1$ & $27.8 \pm 3.1$ & $28.1 \pm 2.4$ \\
\cline { 2 - 6 } & Twice weekly Dose & $25.3 \pm 1.6$ & $26.2 \pm 1.8$ & $27.9 \pm 2.8$ & $28.6 \pm 2.6$ \\
\hline \multirow{2}{*}{ Reticulocyte Count } & Daily Dose & $28.4 \pm 2.1$ & $29.6 \pm 2.9$ & $30.6 \pm 3.2$ & $32.2 \pm 1.6$ \\
\cline { 2 - 6 } & Twice weekly Dose & $29.6 \pm 2.4$ & $30.8 \pm 3.1$ & $31.6 \pm 1.8$ & $32 . \pm 1.8$ \\
\cline { 2 - 6 } & Twice weekly Dose & $1.38 \pm 0.6$ & $1.89 \pm 0.8$ & $2.4 \pm 0.6$ & $2.6 \pm 0.9$ \\
\hline
\end{tabular}

\section{Discussion}

Long terms iron deficiency result in iron deficiency anemia due to imbalance between iron absorption and requirements. Importance of IDA in pregnancy and its treatment has been reported widely. Iron deficiency result not only in the short terms effects on mother and developing fetus but the long terms effects have been reported (WHO 2002 and James et. al., 2009). This study aims to provide data regarding effects of two different regimen oral iron on Hemoglobin concentration and erythrocyte indices during pregnancy. During pregnancy, physiological changes in hemodynamic state leads to hemodilution. Hemodilution is basically due to increase in plasma volume that exceeds RBC count (Jaun et al. 2004). This is much evident during mid pregnancy. This hemodilution results in decrease of Erythrocytes indices but within normal physiological limits. It has been postulated that this plasma expansion is particularly a source for better blood circulation to placenta and ultimately to fetus (Ziaei et.: al, 2007). With the improvement of Hemoglobin concentration, oxygen carrying capacity of RBCs increase and ultimately more oxygen is provided to the tissues. RBC production is stimulated by erythropoietin production. Altered oxygen supply stimulates erythropoietin production, Altered Oxygen supply stimulates erythropoietin from kidneys.

In present study iron supplements, both daily or weekly not only improved Hemoglobin 


\section{JMSCR Vol||06||Issue||06||Page 931-934||June}

concentration but also effects erythrocytes indices. Like many previous studies this study showed physiological macrocytosis (Mukhopaddhay et al., 2004; Taylor and lind 1976). When macrocytosis is within normal physiological limits its quite safe but studies have reported that iron induced macrocytosis could result in increased blood viscosity with impaired blood perfusion of placenta. This might explain why high materials Hemoglobin levels are related to low birth weights, preterm and small for gestational age babies (Lao et aol. 2000 and scanlon et al., 2000) When above result are considered, intermittent iron supplementation seems to be good choice to prevent or treat anemia (Mukhodaphaday et al., 2004. Result of present study favors intermittent iron supplementation not only on the basis of Hemoglobin value but has considered RBC indices for the effectiveness of treatment regimen. Limitations of study were use of oral iron only and the facts that only urban population with non vegetarian diet were recruitment for the study. Also folic acid supplementation was not included in the trial which might result in macrocytosis as data shows that folate anemia and mixed anemia's are still seen in pregnant women (Bux et al, 2003).

\section{Conclusion}

In Iron Deficiency Anemia of pregnancy intermittent iron supplementation has greater increase in hemoglobin level whereas daily iron supplementation results in greater increase in RBC volume.

\section{References}

1. Klevay, L.M. (2001). Iron over J. Trace Elm. Med. Binal, 14 237-240

2. Lao, T.T., Tarn, K.F. and Chan, L.Y. (2000). Third Trimester iron status and pregnancy outcome in non anemic women; pregnancy unfavorably affected by maternal iron excess. Huma, Reprod, 15:1843-1848

3. Murray - Kob L.E. and Beard, J.L. (2007). Iron treatment normalized cognitive functioning in young women, A.M. J. Clin. Nutr. 85 (3) : 778-787.

4. Mukhopaddhay. A., Bhatla, N., Kriplane, A., Agawal, N. and Sevena, R. (2004). Erythrocyte induces in pregnancy : effect of intermittent iron supplementation. Natl. Med. J. Indiani 17:135-137

5. Ridwan, E. Schultin, W., Dillon D. and Gross,. R. (1996). Effects of weekly iron supplementation on pregnant Indonesian women are similar to those of daily supplementation Am. J. Clin. Nutr., 63:884-890.

6. Viteri, F.E., and Line, X. (1995). True absorption and retention of supplemental iron is more efficient when iron is administered every 3 days rather daily to iron normal and iron deferent rates. J. Nutrl., 125:82-91. 
